\title{
O FUNDO DISTRITAL DE DESENVOLVIMENTO E A AGRILCULTURA: O CASO DE ESTUDO DAS COMUNIDADES NO DISTRITO DE CHIBUTO, MOÇAMBIQUE
}

\author{
Nelson Maria Rosário ${ }^{1}$ \\ Daniela Dias Kühn²
}

\begin{abstract}
RESUMO
O presente trabalho analisa a influência do Fundo Distrital de Desenvolvimento (FDD) nas comunidades do distrito de Chibuto. A análise foi feita aos mutuários que se beneficiaram do fundo para desenvolver a atividade agrícola. O estudo fez uma breve análise da influência do acesso ao fundo pelos mutuários que o utilizaram para a produção agrícola, buscando o desenvolvimento das comunidades locais. O estudo combinou a abordagem qualitativa e quantitativa (com o emprego de questionários e entrevistas). Os resultados mostram que, com o financiamento obtido pelos mutuários, houve uma melhoria considerável nos índices de produção e produtividade, assistiuse a uma significativa melhora nas condições básicas na comunidade.
\end{abstract}

Palavras-chave: Fundo Distrital de Desenvolvimento (FDD), agricultura e desenvolvimento, Moçambique.

\section{THE DISTRICT DEVELOPMENT FUND AND AGRICULTURE: THE ESTUDY CASE OF THE COMMUNITIES OF, CHIBUTO DISTRICT, MOZAMBIQUE}

\begin{abstract}
The present work analyzes the influence of the District Development Fund (FDD) in the communities of the district of Chibuto. The analysis was made to borrowers who benefited from the fund to develop agricultural activity. The study made a brief analysis of the influence of access to the fund by borrowers who used it for agricultural production, seeking the development of local communities. The study combined a qualitative and quantitative approach (with the use of questionnaires and interviews). The results show that, with the financing obtained by the borrowers, there was a considerable improvement in the production and productivity indices, and there was a significant improvement in the basic conditions in the community.
\end{abstract}

Keywords: District Development Fund (FDD), agriculture and development, Mozambique.

\footnotetext{
${ }^{1}$ Graduado em ensino de Geografia (UPM). Mestrado em Geografia (UFRN). Doutorando em Desenvolvimento Rural (UFRGS). Professor da Universidade Eduardo Mondlane (UEM). E-mail: nemaro17@gmail.com

2 Graduada em Ciências Econômicas (UFRGS), Mestrado e Doutorado em Desenvolvimento Rural (PGDR/UFRGS). Professora Permanente do Programa de Pós-Graduação em Desenvolvimento Rural (PGDR) da Universidade Federal do Rio Grande do Sul (UFRGS). E-mail: daniela.kuhn@ufrgs.br
} 


\section{INTRODUÇÃO}

O governo moçambicano no seu esforço de combate a pobreza absoluta, definiu o distrito como "polo de desenvolvimento", numa clara estratégia de reduzir as assimetrias no desenvolvimento nacional e aumentar a produtividade interna dos distritos e, desta forma, ter o país inteiro em condições para reduzir e erradicar a pobreza absoluta ao mesmo tempo em que se reduziria a dependência externa (INÁCIO, 2007). Várias razões levaram o governo a considerar o distrito como "polo de desenvolvimento". Uma delas considera que a pobreza é mais concentrada nas zonas rurais do país, dado que mais de $80 \%$ das famílias residem nas respectivas áreas rurais e destas $82 \%$ são pobres (SITOE, 2005).

Portanto, é nestas zonas rurais, onde a população vive principalmente de atividade agrárias de pequena escala, que pode ser encontrada uma heterogeneidade de atividades econômicas relacionadas à geração de rendimento dentro das famílias. A produção de alimentos para o consumo, constitui a base principal da estrutura produtiva desta população pobre.

De modo geral, a agricultura é a principal atividade praticada pelas famílias rurais como forma de garantir sua alimentação e geração de rendimento para satisfação de outras necessidades, através da venda dos seus excedentes. Entretanto, a sua produção, assim como a produtividade é baixa devido a vários fatores entre os quais se pode destacar a agricultura de sequeiro, praticada com fraca utilização de tecnologias modernas, baixo nível de acesso aos serviços de extensão, entre outros aspetos (SITOE, 2005).

$\mathrm{Na}$ tentativa de reverter o cenário, várias foram as estratégias criadas e adotadas pelo governo com vista ao desenvolvimento da agricultura. O Governo, no âmbito da descentralização administrativa e política, criou em 2005, o Orçamento de Investimento de Iniciativas Locais (OIIL), vulgarmente designado por "7 milhões", e hoje concebido como Fundo Distrital de Desenvolvimento (FDD). Esse fundo é reconhecido como reforço aos investimentos destinados à promoção do desenvolvimento econômico e social das populações, principalmente as rurais.

Para Vala (2009, p.13), "o Fundo de Desenvolvimento Distrital é considerado uma medida necessária, que vai ao encontro dos anseios da população, uma vez que permite um maior empoderamento das comunidades locais, envolvendo-as, deste modo, no processo de desenvolvimento local e do País".

No distrito de Chibuto, o FDD coloca à disposição da população local um montante de recursos através de financiamento, estimulando, deste modo, a criação de riqueza no distrito pelo aumento da produção e da produtividade, criação de empregos, incluindo autoemprego. Desde a sua implementação, anualmente o FDD tem vindo a financiar projetos de vários setores, dos quais o setor da agricultura faz parte.

É neste âmbito, que o presente artigo procura analisar a influência do Fundo Distrital de Desenvolvimento na atividade agrícola e no bem-estar das comunidades do posto administrativo Sede, distrito de Chibuto, província de Gaza, Moçambique.

\section{A CONSTRUÇÃO HISTÓRICA DO CONCEITO DE DESENVOLVIMENTO: DIFERENTES ABORDAGENS}

Segundo Santos (2012, p.46), "a origem do conceito de desenvolvimento surge na biologia, empregado como processo de evolução dos seres vivos para o alcance de suas potencialidades genéticas. Com Darwin, a palavra passou a ter uma concepção de transformação, vista como um movimento na direção da forma mais apropriada. Um organismo se desenvolve à medida que progride em direção à sua 
maturidade biológica". A transferência da biologia para a vida em sociedade ocorreu nas últimas décadas do século XIX e tomou corpo com o darwinismo social. Com ela, verificou-se que o progresso, a expansão e o crescimento não eram virtudes intrínsecas ou inerentes a todas as sociedades humanas, mas sim propriedades específicas de algumas sociedades ocidentais. Essas sociedades obtiveram o status de desenvolvidas, o que faz entender que elas eram capazes de produzir os seus próprios movimentos para o alcance do seu bem-estar.

Hoje, para melhor compreender o significado do processo de desenvolvimento na sociedade contemporânea, devem-se levar em consideração as dimensões econômicas, política, social e ambiental. Porém, entende-se que tal conceito não pode ser visto de forma fragmentada, já que todas essas dimensões estão presentes e se relacionam simultaneamente.

Segundo Oliveira, Vieira e Pauli (2018, p.30), "a diferenciação dos conceitos de desenvolvimento e crescimento intensificou-se com a Segunda Guerra Mundial, pois com a guerra muitos países ficaram com sua estrutura social, econômica e política desestabilizada".

Para Veiga (2001, p.104), "o sentido do termo desenvolvimento, não costuma ser explicitado, apesar de seu emprego ser tão frequente. Sempre se imagina que será bem entendido. Raros são os que se arriscam em explicar o seu real significado". Segundo o mesmo autor, citando Robinson (Sd), pode-se fazer uma comparação do conceito de desenvolvimento ao de elefante, ao afirmar que seja: 'difícil de definir, mas muito fácil de reconhecer', ou seja, se por um lado há a banalização no uso desse conceito, por outro lado há uma intensa dificuldade em abordá-lo em termos teóricos e metodológicos, principalmente no meio acadêmico.

Ainda Veiga (2001, p.104) afirma que "o desenvolvimento corresponde à ampliação das possibilidades de escolha, não apenas de modelos de automóvel ou canais de televisão, mas, sobretudo das oportunidades de expansão das potencialidades humanas que, dependem de fatores socioculturais, como saúde, educação, comunicação, direitos e liberdade".

Portanto, fica bem apresentado que o desenvolvimento deve ser visto como um processo de expansão das liberdades reais desfrutadas pelas pessoas. Isso contrasta com visões mais restritas, como as que identificam o desenvolvimento como crescimento do PIB, aumento da renda per capita, industrialização, avanço tecnológico ou modernização. Importa realçar que esses elementos são obviamente importantes como meios de expandir as liberdades e que as liberdades são essencialmente determinadas por saúde, educação e direitos civis.

De acordo com Sachs (2004, p.37), "o desenvolvimento pretende habilitar cada ser humano a manifestar potencialidades, talentos e imaginação, na procura da auto realização e da felicidade, mediante empreendimentos individuais e coletivos, numa combinação de trabalho autônomo e heterônomo e de tempo dedicado a atividades não produtivas". A boa sociedade é aquela que maximiza essas oportunidades, enquanto cria, simultaneamente, um ambiente de convivência e, em última instância, condições para a produção de meios de existência viáveis, suprindo as necessidades materiais básicas da vida - comida, abrigo, roupas - numa variedade de formas e de cenários - famílias, redes e comunidades (SACHS 2004).

Para Sen (2000), uma concepção adequada de desenvolvimento deve ir muito além de variáveis relacionadas à renda. $O$ desenvolvimento deve estar relacionado, principalmente, com a melhoria da vida que levamos e das liberdades que desfrutamos. É fator incontestável na sociedade pós-industrial, a preocupação com a implementação de modelos de desenvolvimento social que diminuam o grande "gap" existente entre ricos e pobres. 
O novo paradigma de desenvolvimento pode ser visto de maneira bastante simplificada: "desenvolvimento deve melhorar a vida das pessoas (desenvolvimento humano), de todas as pessoas (desenvolvimento social), das que estão vivas hoje e das que viverão no futuro (desenvolvimento sustentável) (FRANCO, 2000, p. 36). Importa ainda lembrar que Sen (2000, p. 29) afirma que "o crescimento econômico não pode sensatamente ser considerado um fim em si mesmo. $O$ desenvolvimento tem de estar relacionado, sobretudo, com a melhora da vida que levamos e das liberdades que desfrutamos".

Sen (2000) vê o desenvolvimento como um processo de expansão das liberdades reais que as pessoas desfrutam. A abordagem do desenvolvimento através da liberdade, obtida pela expansão das capacitações, tem implicações no processo de desenvolvimento igualitário e no respeito à vontade das pessoas. Nessa abordagem, a expansão da liberdade é considerada um fim primordial e o principal meio para o desenvolvimento.

A expansão das capacitações, o processo de desenvolvimento, admitido como uma melhoria da qualidade de vida das pessoas, só pode ser "documentada" a partir da identificação de um aumento das oportunidades de escolhas dos agentes sociais. Esse acesso a mais oportunidades de escolhas, significaria ao agente social uma possibilidade de incrementar suas capacitações.

Nessa tentativa de compreensão dos processos sociais, Amartya Sen (2000) indica que é preciso, em primeiro lugar, distinguir claramente o que pode ser considerado como um meio e um fim em relação ao processo de desenvolvimento. É a essa indeterminação que está associada à confusão entre prosperidade econômica e desenvolvimento.

Segundo Sen (1993, p.135):

Há, portanto, duas questões diferentes aqui. Primeiro: a prosperidade econômica é apenas um dos meios para enriquecer a vida das pessoas. É uma confusão no plano dos princípios atribuírem a ela o estatuto de objetivo a alcançar. Segunda: mesmo como um meio, o mero aumento da riqueza econômica pode ser ineficaz na consecução de fins realmente valiosos. Para evitar que o planejamento do desenvolvimento e o processo de formulação de políticas em geral sejam afetados por custosas confusões de fins e meios, teremos de enfrentar a questão da identificação dos fins, nos termos dos quais a eficácia dos meios possa ser sistematicamente avaliada [...].

Partindo dessa diferenciação fundamental entre meios e fins para análise e compreensão do processo de desenvolvimento, o autor procura apresentar alguns conceitos que representam a base teórica para essa abordagem. O conceito fundamental da abordagem das capacitações é o de funcionamentos. Este conceito está associado a atividades/ações, por exemplo, comer, ler, escrever, ou a estados de existência, por exemplo, estar bem nutrido, não estar exposto a doenças evitáveis (SEN, 2000).

No pensamento de Sen (2000, p. 15), "a expansão das liberdades substantivas é vista não somente como os fins, mas também o meio necessário para se alcançar o desenvolvimento: a) fim primordial, pois tem um papel constitutivo e enriquece a vida humana e o desenvolvimento; b) principal meio do desenvolvimento através do seu papel instrumental".

O desenvolvimento requer que se removam as principais fontes de privação de liberdade: "pobreza e tirania, carência de oportunidades econômicas e destituição 
social, negligência dos serviços públicos e intolerância ou interferência excessiva dos estados repressivos" (SEN, 2000).

Ainda para este autor, a liberdade (assim como a participação) é central para o processo de desenvolvimento. Primeiro porque a avaliação do progresso, segundo ele, tem de ser feita verificando, primordialmente, se houve aumento das liberdades das pessoas. Segundo porque a realização do desenvolvimento depende inteiramente da livre condição de agente das pessoas.

Para a expansão das liberdades substantivas individuais, Amartya Sen (2000) focaliza duas saídas: a primeira está em condicionar o crescimento econômico a uma melhoria de vida da população em geral, ou seja, partilhar os frutos do crescimento. A segunda é através de políticas públicas eficientes, orientadas para melhorar a condição de agente do indivíduo.

O desenvolvimento pode ser a ação de tornar-se mais avançado ou mais organizado. Em outra abordagem, numa visão mais complexa, um processo multidimensional, que envolve a reorganização e a reorientação completa dos sistemas econômicos ou social. Porém, a perspectiva redefine o desenvolvimento como um processo multidimensional, que envolve mudanças nas estruturas, nos comportamentos e nas instituições, bem como na aceleração do crescimento econômico, na redução das desigualdades e na erradicação da miséria.

O desenvolvimento deve contemplar o estudo de variáveis de diversas origens, a incluir a renda e indicadores referentes à qualidade de vida das pessoas, como o acesso à educação e saúde, desigualdade e demais fatores que interferem no bem-estar da população (OLIVEIRA, 2018).

Portanto, o desenvolvimento deve ser encarado como um processo complexo de mudanças e transformações de ordem econômica, política e, principalmente, humana e social.

\section{UM OLHAR AO ORÇAMENTO DE INVESTIMENTO DE INICIATIVA LOCAL OU FUNDO DE DESENVOLVIMENTO DO DISTRITO}

Em 2006, o Governo de Moçambique introduziu o Orçamento de Investimento de Iniciativa Local (OIIL) ${ }^{3}$, popularmente conhecido por "7 Milhões" contribuir para a redução da pobreza através do financiamento de projetos individuais de produção de comida e de geração de emprego e renda. A implementação dos iniciativos "7 Milhões" criou um debate nacional sobre as motivações, o conteúdo, direção, instrumentos e impacto de políticas e estratégias públicas. Os temas do debate são variados, cobrindo áreas como a justificação e concepção da iniciativa, metodologias de análises de impactos, a polêmica sobre a base estatística gerada, problemas na implementação (especialmente as fracas taxas de reembolsos e desvios de aplicação), aproveitamento político da iniciativa, etc.

\footnotetext{
${ }^{3}$ O OIIL foi criado pela Lei $n^{0} 12 / 2005$, de 23 de Dezembro, que aprovou o orçamento de Estado para o ano 2006. Esta lei fixa um limite orçamental de investimento público de iniciativa privada cuja responsabilidade de execução era delegada aos governos distritais. Esses projetos deviam obedecer a um princípio que era o da produção de comida e geração de renda e com impacto junto às populações locais. Contudo, é preciso realçar que o lançamento do OIIL foi resultado de um longo processo e debate ideológico de descentralização em Moçambique, cuja operacionalização mais agressiva está patente na Lei 08/2003 de 19 de Maio (Lei dos Órgãos Locais de Estado, LOLE) e o Decreto do Conselho de Ministros n¹1/2005, de 10 de Junho, que aprova o Regulamento da Lei dos Órgãos Locais do Estado (RELOLE).

${ }^{4} \mathrm{O}$ nome popular do OIIL, 7 milhões, surge pelo fato de, nos seus primeiros anos, terem sido atribuídos 7 milhões de meticais (254.105.95 USD) a cada distrito rural, independentemente das características econômicas, demográficas e territoriais do distrito. Ao longo do tempo, os montantes monetários foram alterados significativamente e já não são idênticos para todos os distritos. Mas o nome popular, sete milhões, continua prevalecendo.
} 
Em finais de 2009, o OIIL foi transformado em Fundo Distrital de Desenvolvimento (FDD), com personalidade jurídica, autonomia administrativa e financeira, gerido localmente. O FDD é tutelado pelo Governador provincial que homologa os planos e relatórios de atividades, autoriza a recepção de donativos e abertura de contas e realiza inspeções regulares. A execução das atividades do FDD é de responsabilidade dos Conselhos Consultivos Distritais (CCD). Assim, o FDD pode recorrer aos reembolsos, às subvenções do Estado, donativos e fundos comunitários para dar crédito às pessoas pobres (CONSELHO DE MINISTROS, 2009).

De acordo com o regulamento do fundo, as atividades a serem financiadas, adotando juros bonificados, são aquelas que visam estimular o empreendedorismo local, atividades de produção e comercialização de alimentos, geração de emprego e renda e outras atividades produtivas.

Trata-se de um orçamento de grande impacto que serve de alavanca para o desenvolvimento do País, ao colocar à disposição dos agentes econômicos recursos para o investimento, estimulando, deste modo, a criação de riqueza nos distritos pelo aumento da produção e da produtividade e criação de empregos, incluindo autoemprego. Porém, é importante referir que com a divulgação feita pelos órgãos de comunicação social, bem como a campanha boca a boca e discursos políticos, esperava-se que o projeto servisse de impulso para as comunidades com maior grau de vulnerabilidade.

A este respeito, Valá (2009, p. 13) entende que "o orçamento de investimento veio reforçar a concepção de que o "distrito é polo de desenvolvimento", e assegurar um instrumento concreto de intervenção que permita a adoção de mecanismos locais para o desenvolvimento do distrito".

\section{METODOLOGIA}

O presente trabalho adotou uma abordagem quantitativa e qualitativa descritiva, empregando-se o estudo de caso. Do ponto de vista dos procedimentos técnicos, foram selecionados a pesquisa bibliografia e documental. A pesquisa bibliográfica consistiu em obter informação a partir de material já publicado em livros, artigos científicos, monografias, dissertações, teses e planos do Governo de Moçambique.

A recolha de dados foi feita com base em entrevistas semiestruturadas com gestores do fundo do FDD no Governo do distrito de Chibuto e inquérito constituído por questões fechadas e abertas aplicadas aos agricultores mutuários do FDD do Posto Administrativo Sede, envolvendo uma amostra de 25 mutuários. Em relação aos métodos e técnicas de amostragem, os elementos da amostra foram selecionados através de métodos e técnicas de amostragem probabilística e não probabilísticas, a aleatória simples e Snow Ball. Após a coleta, o tratamento para a formação da base de dados envolveu a utilização de planilhas eletrônicas em que foi possível organizar as tabelas e gráficos que constituem a próxima seção.

\section{ANÁLISE E DISCUSSÃO DOS RESULTADOS}

Segundo dados do governo do distrito de Chibuto, de 2010 a 2016, em todo o distrito, foram financiados, no total, 777 projetos dos quais $165(21,24 \%)$ destinouse a agricultura e o remanescente aos outros setores privilegiados pelo FDD. Dos projetos destinados a produção agrícola (165), somente 25 projetos $(15,15 \%)$ foram financiados a nível do Posto Administrativo Sede. A partir da visão geral do fundo no distrito, as seções apresentam algumas dimensões que permitem a análise do FDD como elemento motivador do processo de desenvolvimento da comunidade. 


\subsection{VISÃO GERAL DO FDD NO DISTRITO DE CHIBUTO E NO POSTO ADMINISTRATIVO SEDE}

\subsubsection{Alocação do fundo no distrito e sua repartição nos postos administrativos}

Em termos gerais, no período de 2010 a 2016, os cofres do FDD ao nível do distrito de Chibuto, receberam acima dos habituais sete milhões ${ }^{5}$ de meticais que foram alocados anualmente (Gráfico 01).

Gráfico 1 - Evolução do valor alocado pelo FDD no distrito de Chibuto e no Posto Administrativo Sede (PAS)

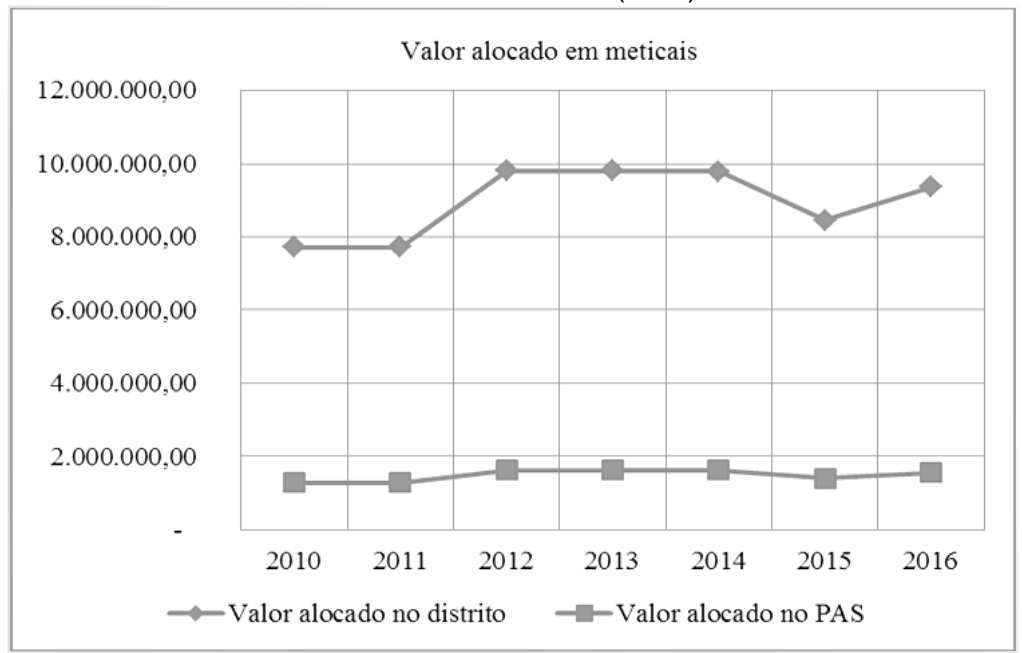

Fonte: Trabalho de campo, 2017. Elaboração dos autores.

Da tabela 01, verifica-se que nos últimos sete anos, o Governo disponibilizou cerca de $62.632 .230,00^{6}$ de meticais para financiar diferentes projetos propostos pelos residentes do distrito. Os anos 2012, 2013 e 2014, foram aqueles em que o Governo mais disponibilizou recursos para o FDD, correspondentes a $15,64 \%$ do total recebido no respectivo ano. Do valor alocado anualmente ao distrito, o mesmo era redistribuído a cada um dos Postos Administrativos de forma equitativa.

\footnotetext{
${ }^{5}$ Valor financiado em todos os distritos no início da implementação da estratégia do FDD.

6 - 1.026.600 USD. A conversão foi feita no site http://financeone.com.br/moedas/conversor-demoedas?f=Mocambique\&t=Estados\%20Unidos, feita em 15 de Outubro de 2018, a taxa utilizada foi 3,169.
} 
Tabela 01 - Valor alocado no FDD a nível do Distrito de Chibuto e seus PAS (em meticais)

\begin{tabular}{|c|c|c|c|c|}
\hline \multirow[b]{2}{*}{ Ano } & \multicolumn{2}{|c|}{ Valor Alocado (em meticais) } & \multirow[b]{2}{*}{$\%$} & \multirow{2}{*}{$\begin{array}{c}\text { Variação } \\
\text { (\%) }\end{array}$} \\
\hline & Distrito de Chibuto & Posto Administrativo & & \\
\hline 2010 & $7.720 .000,00$ & $1.286 .666,67$ & 12,33 & - \\
\hline 2011 & $7.720 .000,00$ & $1.286 .666,67$ & 12,33 & 0,00 \\
\hline 2012 & $9.798 .000,00$ & $1.633 .000,00$ & 15,64 & 26,92 \\
\hline 2013 & $9.798 .000,00$ & $1.633 .000,00$ & 15,64 & 0,00 \\
\hline 2014 & $9.783 .480,00$ & $1.630 .580,00$ & 15,62 & $-0,15$ \\
\hline 2015 & $8.457 .520,00$ & $1.409 .586,67$ & 13,50 & $-13,55$ \\
\hline 2016 & $9.355 .230,00$ & $1.559 .205,00$ & 14,94 & 10,61 \\
\hline Total & $62.632 .230,00$ & $10.438 .705,00$ & 100,00 & - \\
\hline
\end{tabular}

Fonte: Trabalho de campo, 2017. Elaboração dos autores.

Importa aqui salientar, que, tanto para o distrito de Chibuto assim como para o Posto Administrativo Sede, o valor alocado anualmente oscilava em igual proporção visto que a repartição do fundo era, e continua sendo, equitativa para os 06 postos administrativos que a constituem. Por exemplo, em 2011 e 2013, o valor alocado manteve-se em relação ao ano anterior, mas em 2014 e 2016 houve um decréscimo. As subidas somente foram verificadas no em $2016 \mathrm{com}$ um percentual de $10,61 \%$. O ano em que houve maior variação positiva foi em 2012, com $26,92 \%$ de crescimento no volume de recursos distribuídos. Este foi o ano que o volume de recursos atingiu 0 seu máximo.

Pode-se salientar que a divisão do fundo é feita equitativamente sem se tomar em consideração as necessidades e potencialidades oferecidas por cada um dos Postos Administrativos, como por exemplo o número de habitantes por posto administrativo; o número de projetos submetidos a cada PA, entre outros aspetos relevantes que poderiam ser levados em conta no processo da repartição do valor financiado.

\subsubsection{SETORES PRIORITÁRIOS FINANCIADOS PELO FDD NO POSTO ADMINISTRATIVO SEDE}

Em termos gerais, são apresentados oito setores distintos contemplados no FDD, os quais os residentes a nível distrital devem levar em consideração durante a elaboração dos seus projetos a fim receberem empréstimos. Esses setores são identificados por projetos prioritários que possam gerar renda e produzir comida, nomeadamente, o setor da agricultura, agro-processamento, comércio, indústria, pecuária, pesca, serviços e turismo.

Em cada um dos setores, existem atividades específicas que, ao longo destes anos, os Conselhos Consultivos tanto a nível local como do Posto Administrativo e Distrital, julgavam viáveis e que mereciam ser financiadas (Quadro 01). 
Quadro 01 - Atividades financiadas pelo FDD no Posto Administrativo Sede, de 2010 a 2016.

\begin{tabular}{|c|c|}
\hline Setor & $\begin{array}{l}\text { Tipo de Atividades Financiadas } \\
\end{array}$ \\
\hline Agricultura & $\begin{array}{l}\text { Produção de cereais e hortícolas; Aquisição de insumos, insumos e } \\
\text { maquinaria agrícolas. }\end{array}$ \\
\hline Agroindústria & Moageiras; \\
\hline Comércio & $\begin{array}{l}\text { Comercialização de insumos agrícolas, produtos de } \\
\text { necessidade, artigos domésticos, material de construção, carvão, } \\
\text { produtos farmacêuticos e eletrodomésticos; estaleiros. }\end{array}$ \\
\hline Indústria & Serralharias, panificadoras, alfaiataria, estofarias, carpintaria \\
\hline Pecuária & Criação de gado bovino e de suínos; Produção de frangos, patos, e leite; \\
\hline Pesca & Pesca artesanal \\
\hline Serviços & $\begin{array}{l}\text { Serviços hoteleiros; Abastecimento de água; serviços de tração animal; } \\
\text { Aquisição de Juntas; salão de cabeleireiro e de beleza; estúdios } \\
\text { fotográficos; serviços de limpeza e decorações. }\end{array}$ \\
\hline Turismo & (Não foram financiadas atividades neste setor) \\
\hline
\end{tabular}

A nível do distrito foram financiados cerca de 777 projetos pelo fundo dos sete milhões durante o período em análise, 165 correspondem a projetos ligados à produção de comida (agricultura) e o remanescente, aos restantes setores. Desses projetos aprovados, 74\% foram atribuídos a mutuários do sexo masculino e apenas 26\% a mulheres, conforme apresentado no Gráfico 2.

Gráfico 02 - Distribuição dos projetos ao longo dos anos 2010 a 2016 por gênero em Chibuto

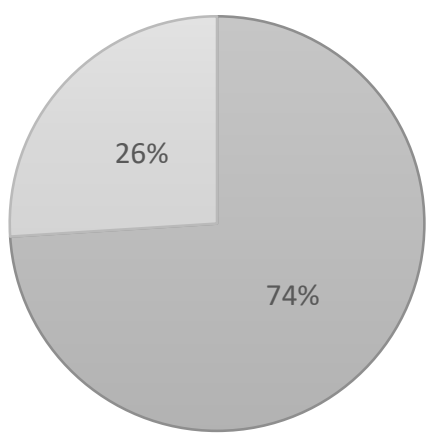

$\square$ Homens $\square$ Mulheres

Fonte: Trabalho de campo, 2017. Elaborado pelos autores.

De acordo com o Instituto Nacional de Estatística (2013), o distrito conta com cerca de 213.323 habitantes, dentre eles $54,5 \%$ correspondentes a mulheres e 0 remanescente homens. Não foram encontradas evidências suficientes que expliquem essa desigualdade ao financiar mais homens em relação a mulheres.

Quando questionado os Conselhos Consultivos Distritais (CCD) sobre os motivos dessa desigualdade de gênero no concernente à atribuição dos financiamentos foram pouco claros ao afirmar que: "Pressupomos que sejam os do 
sexo masculino que submeteram mais projetos em relação as mulheres, que preferem dedicar a sua vida a atividades domésticas" (Trabalho de campo). Outras razões que podem estar por detrás desta situação constatada é a questão do índice elevado de analfabetismo que é maior na população do sexo feminino. Isso faz com que muitas das mulheres não consigam elaborar o seu projeto para remeter ao conselho consultivo para sua posterior aprovação. Outro motivo refere-se a questões culturais, geralmente quando se trata de acessar ao financiamento, as mulheres preferem por o nome do seu marido, mesmo sabendo que não é ele que estará em frente do empreendimento ou projeto.

No Posto Administrativo Sede, durante o período em análise, em média, foram financiados cerca de 27 projetos por ano de todos os setores num total de 191 (Gráfico 3).

Gráfico 3 - Evolução do número de projetos financiados anualmente no Posto Administrativo Sede

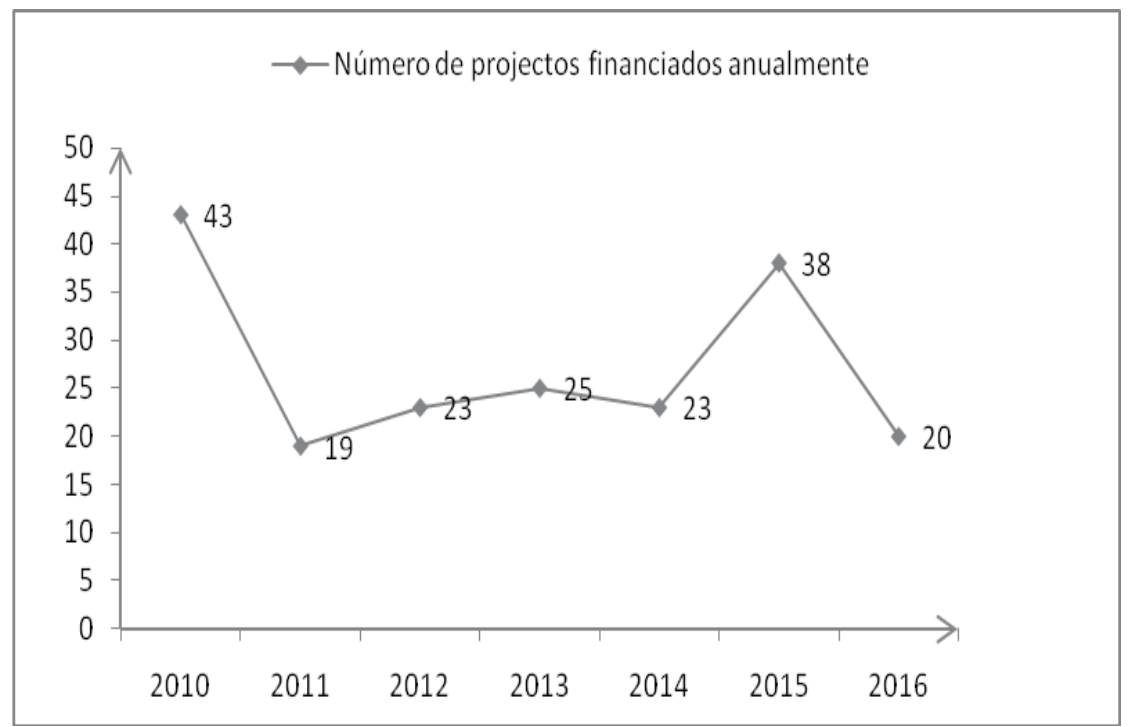

Fonte: Trabalho de campo, 2017. Elaborado pelos autores

Note que com base na conjugação dos dados do gráfico 01 e 03, verifica-se que 2010 foi o ano com mais projetos financiados, mas com valor alocado mais baixo em relação aos outros anos ${ }^{7}$. Situação inversa verifica-se no ano 2012 em que FDD teve aumento de recursos com redução no número de projetos financiados.

Do total de projetos financiados neste período em análise, o Posto Administrativo Sede financiou mais projetos ligados ao setor do comércio e da pecuária, correspondendo a $47 \%$ e $26 \%$, respectivamente. O terceiro setor que conta com mais projetos aprovados pelo FDD durante estes sete anos é o dos serviços, com uma quota de $10 \%$. Os demais setores registaram frações menores, são o setor da

\footnotetext{
7 Importa aqui referir, que todos os projetos aprovados no ano 2012 foram financiados, entretanto os valores recebidos pelos beneficiários do programa nem sempre corresponderam ao orçamento feito originalmente nos projetos entregues ao conselho consultivo distrital para efeito de financiamento. Dessa forma, constitui-se uma evidente dificuldade de execução dos projetos.
} 
agricultura, da indústria, do agroprocessamento, e das pescas, com cerca de $8 \%, 5 \%$, $3 \%, 1 \%$, respectivamente (Tabela 02 ).

Ainda na Tabela 02, pode-se observar que o mesmo aconteceu com os montantes alocados a cada setor. Do valor financiado durante esses anos, $37 \%$ foram alocados ao setor do comércio seguidos dos $27 \%$ e $10 \%$ do setor da pecuária e serviços; e em média cada projeto agrícola era financiado com o montante de $90.109,31$ meticais. Percebe-se que há uma amplitude grande entre os valores financiados por tipo de projeto. O setor que obteve o maior volume de recursos, o comércio, também tem a maior quantidade de projeto e a menor média de valor por projeto, indicando a capilaridade possível desse setor. O setor que demandou o maior volume de recursos por projeto aprovado foi o da pesca. A Tabela 02 apresenta detalhadamente as informações para cada setor.

Tabela 02 - Número de projetos e valor financiado em cada setor pelo FDD, entre 2010-2016, no Posto Administrativo Sede

\begin{tabular}{c|c|c|c|c|c}
\hline Setor & $\begin{array}{c}\mathbf{N}^{\circ} \text { de } \\
\text { Projetos } \\
\text { financiados }\end{array}$ & $\begin{array}{c}\% \text { de } \\
\text { Projetos } \\
\text { financiados }\end{array}$ & $\begin{array}{c}\text { Valor } \\
\text { Financiado } \\
\text { (Meticais) }\end{array}$ & $\begin{array}{c}\% \text { do } \\
\text { valor } \\
\text { Financia } \\
\text { do }\end{array}$ & $\begin{array}{c}\text { Financiamento } \\
\text { Médio/Projeto }\end{array}$ \\
\hline Agricultura & 16 & $8 \%$ & $1.441 .749,00$ & $10 \%$ & $90.109,31$ \\
\hline Agroindústria & 5 & $3 \%$ & $574.000,00$ & $4 \%$ & $114.800,00$ \\
\hline Comercio & 89 & $47 \%$ & $5.266 .073,68$ & $37 \%$ & $59.169,37$ \\
\hline Industria & 10 & $5 \%$ & $1.023 .910,00$ & $7 \%$ & $102.391,00$ \\
\hline Pecuária & 50 & 26 & $3.790 .395,00$ & 27 & $75.807,90$ \\
\hline Pesca & 2 & 1 & $350.000,00$ & 2 & $175.000,00$ \\
\hline Serviços & 19 & 10 & $1.657 .841,85$ & 12 & $87.254,83$ \\
\hline Turismo & 0 & - & - & - & - \\
\hline Total & 191 & $\mathbf{1 0 0}$ & $\mathbf{1 4 . 1 0 3 . 9 6 9 , 5 3}$ & $\mathbf{1 0 0}$ & $\mathbf{7 3 . 8 4 2 , 7 7}$ \\
\hline
\end{tabular}

Fonte: Trabalho de campo, 2017. Elaborado pelos autores.

A agricultura que é tida como a principal fonte de renda da população de Chibuto, encontra-se sempre, ao longo do período estudado, atrás de outros setores, tanto na quantidade de projetos quanto no percentual de recursos empregado no setor ( $10 \%$ do total de recursos). O setor do turismo nunca foi financiado pelo FDD, provavelmente porque ou nunca foram submetidos propostas de projetos com esse propósito ou os projetos propostos pelos habitantes da localidade não foram aprovados.

De forma a se ter uma visão mais elucidativa em relação aos setores mais frequentemente financiados foram organizados as tabelas 03 e 04 indicando, por ano acompanhado no período. 
Tabela 03 - Número de projetos financiados pelo FDD em cada um dos setores no PAS

\begin{tabular}{c|c|c|c|c|c|c|c|c}
\hline \multirow{2}{*}{ Setores } & \multicolumn{10}{|c|}{\begin{tabular}{c}
201 \\
\cline { 2 - 9 }
\end{tabular}} & 2010 & 2011 & 2 & $\begin{array}{c}201 \\
3\end{array}$ & $\begin{array}{c}201 \\
4\end{array}$ & $\begin{array}{c}201 \\
5\end{array}$ & $\begin{array}{c}201 \\
6\end{array}$ & Total \\
\hline Agricultura & 4 & 2 & 3 & 0 & 0 & 4 & 3 & 16 \\
\hline $\begin{array}{c}\text { Agroindúst } \\
\text { ria }\end{array}$ & 1 & 0 & 0 & 1 & 1 & 1 & 1 & 5 \\
\hline Comércio & 26 & 2 & 6 & 12 & 8 & 23 & 12 & 89 \\
\hline Indústria & 2 & 3 & 1 & 1 & 2 & 1 & 0 & 10 \\
\hline Pecuária & 7 & 5 & 10 & 10 & 7 & 8 & 3 & 50 \\
\hline Pesca & 0 & 0 & 0 & 0 & 0 & 1 & 1 & 2 \\
\hline Serviços & 3 & 7 & 3 & 1 & 5 & 0 & 0 & 19 \\
\hline Turismo & 0 & 0 & 0 & 0 & 0 & 0 & 0 & 0 \\
\hline Total & 43 & 19 & 23 & 25 & 23 & 38 & 20 & 191 \\
\hline
\end{tabular}

Fonte: Trabalho de campo, 2017. Elaborado pelos autores.

Tabela 04 - Quantia disponibilizada a cada um dos setores pelo FDD no PAS

\begin{tabular}{c|c|c|c|c|c|c|c}
\hline \multirow{2}{*}{ Setores } & \multicolumn{7}{|c}{ Ano } \\
\cline { 2 - 8 } & 2010 & 2011 & 2012 & 2013 & 2014 & 2015 & 2016 \\
\hline Agricultura & 299.405 & 102.900 & 233.000 & 0 & 0 & 460.000 & 341.444 \\
\hline Agroindústria & 90.000 & 0 & 0 & 184.000 & 100.000 & 100.000 & 100.000 \\
\hline Comércio & 390.000 & 190.000 & 534.000 & 629.000 & 603.448 & $\begin{array}{c}2.037 .74 \\
5\end{array}$ & 881.880 \\
\hline Indústria & 170.350 & 443.560 & 100.000 & 50.000 & 160.000 & 100.000 & 0 \\
\hline Pecuária & 401.595 & 558.000 & 810.000 & 770.000 & 480.800 & 535.000 & 0 \\
\hline Pesca & 0 & 0 & 0 & 0 & 0 & 250.000 & 100.000 \\
\hline Serviços & 468.610 & 403.000 & 220.365 & 180.000 & 385.866 & 0 & 0 \\
\hline Turismo & 0 & 0 & 0 & 0 & 0 & 0 & 0 \\
\hline
\end{tabular}

Fonte: Trabalho de campo, 2017. Elaborado pelos autores.

Grande parte dos projetos e dos recursos são disponibilizados para a organização de atividades que envolvem o comércio. Cabe salientar que, nem sempre os valores financiados aos projetos aprovados correspondem aos valores propostos pelos mutuários. Isso acontece porque os mesmos projetos dependem da decisão do Conselho Consultivo do Posto Administrativo. Ou seja, por vezes quando o valor alocado àquele posto é inferior em relação ao número de projetos submetidos, a estratégia é repartir o montante de recursos existente de forma que abranja maior parte deles.

Fazendo uma análise, a questão que surge é: o que é mais vantajoso, financiar inúmeros projetos com montantes que não correspondem (inferiores) aos valores do investimento propostos pelos proponentes, que por conseguinte dificilmente poderiam cobrir os custos logo no início da sua implementação e consequentemente aumentaria a probabilidade de falência do projeto, sem que tenham reembolsado a dívida contraída ao Estado ou financiar somente uma quantidade menor de projetos com valores que correspondem ao investimento proposto, melhorando portanto a possibilidade de realização dos objetivos propostos? 


\subsubsection{A AGRICULTURA E O FINANCIAMENTO DO FDD NO POSTO ADMINISTRATIVO SEDE}

Para que um projeto agrícola seja financiado, os agricultores propõem-no na localidade em que se encontram, neste caso, na localidade de Maniquinique ou Canhavane. Após terem sido analisados pelo Conselho Consultivo da Localidade, os projetos aprovados são propostos ao Posto Administrativo Sede e, por fim, ao Governo do distrito de Chibuto tendo sido analisados respectivamente pelo Conselho Consultivo do posto Administrativo e Conselho Consultivo do Distrito.

Em termos gerais, neste setor, o Posto Administrativo Sede em média, financia por ano aproximadamente 02 a 03 projetos de produção de comida, o que poderia ser considerado pouco se pensarmos que há necessidade de produção de alimento para a população da região. Quando entrevistados os Conselhos Consultivos do Distrito, na tentativa de procurar entender os motivos desde cenário, tendo em conta que a agricultura constitui a principal atividade praticada pela maioria da população residente no distrito, que são pobres e carecem de financiamentos para elevar as suas produções e produtividades por hectare, os mesmos afirmaram que:

[...] Isso sucede quando não são ou são poucos os projetos submetidos para aquele setor ou aquela atividade. [...] Por se tratar de uma atividade de riscos, principalmente o nosso distrito que é muito suscetível a calamidades naturais como secas, ciclones e cheias muitas vezes preferimos não financiar projetos destes setores e apostar nos outros. Por exemplo, em 2013 e 2014 , nenhum projeto agrícola foi financiado devido a cheias que se fizeram sentir, portanto, a ideia foi somente alocar o valor em outras áreas como pecuária pois, quando há enchentes não há problemas de foragem para a alimentação do gado bovino (Membro do Conselho Consultivo Distrital, Maio de 2017).

Se a agricultura é uma atividade de risco, quando questionados sobre quais estratégias o governo adota para monitorar e avaliar o desempenho dos agricultores mutuários do FDD, simplesmente afirmaram que a sua tarefa é o de avaliar, aprovar e financiar o projeto, o resto ficava ao encargo do agricultor, pois, estes tem acesso a assistência técnica dos Serviços Distrital de atividade Econômica.

O máximo que os Conselhos Consultivos fazem no que tange a estratégias para minimizar os riscos da agricultura devido a fatores por eles mencionados anteriormente, é financiar projetos que se localizem nas baixas do Rio Limpopo e em outros locais que tenha água suficiente para irrigar os campos, daí, se incentiva ao mutuário agrícola que adquira moto bombas. Ou seja, se percebe que apenas o acesso ao recurso monetário pode ser, de fato, insuficiente para a execução da atividade proposta no projeto aprovado.

\section{IMPACTO DO FDD NO DESENVOLVIMENTO DA AGRICULTURA E DO BEM- ESTAR NO POSTO ADMINISTRATIVO SEDE}

Tal como é referido por Kohansaletal (2008), o crédito realmente desempenha um papel crucial para a eliminação das restrições financeiras dos agricultores, pois, através do crédito, os mesmos conseguem investir em atividades agrícolas, elevam suas produções e melhoram as tecnologias utilizadas durante 0 processo de produção. Além disso, de acordo com o mesmo autor, a acessibilidade ao crédito é importante pois, contribui na melhoria da qualidade e quantidade dos produtos agrícolas, de modo que pode aumentar a renda dos agricultores. 
Concordando com o autor, de fato existe uma relação entre acessibilidade ao crédito e os níveis de produção agrícola, principalmente em regiões em que a agricultura familiar é mais predominante.

No caso do Posto Administrativo Sede, todos mutuários foram unânimes ao afirmar que a maior parte dos produtos são destinadas ao mercado e a outra parte é para o consumo da família. Do total de mutuários entrevistados, apesar de alguns se sentirem indignados com o valor do financiamento, reduzido em relação à proposta de orçamento do projeto submetido, cerca de $67 \%$ afirmaram ter aumentado seu nível de produção e $73 \%$ elevaram os seus rendimentos após terem sido financiados pelo FDD (gráfico 04).

Gráfico 04: Mudanças verificadas na produção agrícolas e no rendimento dos mutuários após a recepção do FDD.

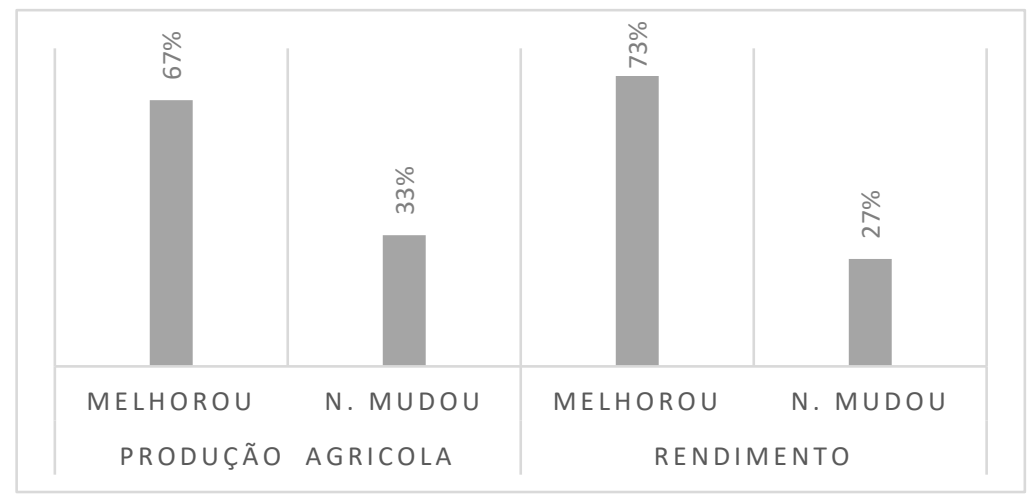

Fonte: Trabalho de campo, 2017. Elaborado pelos autores

Tal como refere Muteia (2014, p.12), "não há nenhum sistema agrícola que se desenvolva sem uma componente de crédito capaz de mantê-lo capitalizado". Para manter ou melhorar os níveis de competitividade requer-se investimentos na lavoura da terra, na construção de sistemas de irrigação, na aquisição de melhor material genético, em instrumentos e equipamentos de produção, na armazenagem, infraestruturas e transporte, e isso só é possível recorrendo ao crédito.

Portanto, foi possível visualizar que com o valor recebido no FDD, os agricultores daquela região, atualmente conseguiram aumentar suas áreas exploradas; diferentemente dos anos anteriores, hoje fazem a utilização de tecnologias melhoradas na produção agrícola tais como, uso de sementes melhoradas que adquirem a nível local, irrigam suas culturas sem depender exclusivamente das condições climatéricas (precipitação), fertilizam seus solos com base em adubos químicos e combatem pragas e doenças que atacam suas culturas com base em agrotóxicos. Houve aumento tanto da produção agrícola como da renda das unidades de produção.

Com os rendimentos resultantes da produção, sempre que possível uma parte do rendimento é utilizada para o pagamento do empréstimo e outra parte para satisfação de necessidades básicas da família (gráfico 05). 


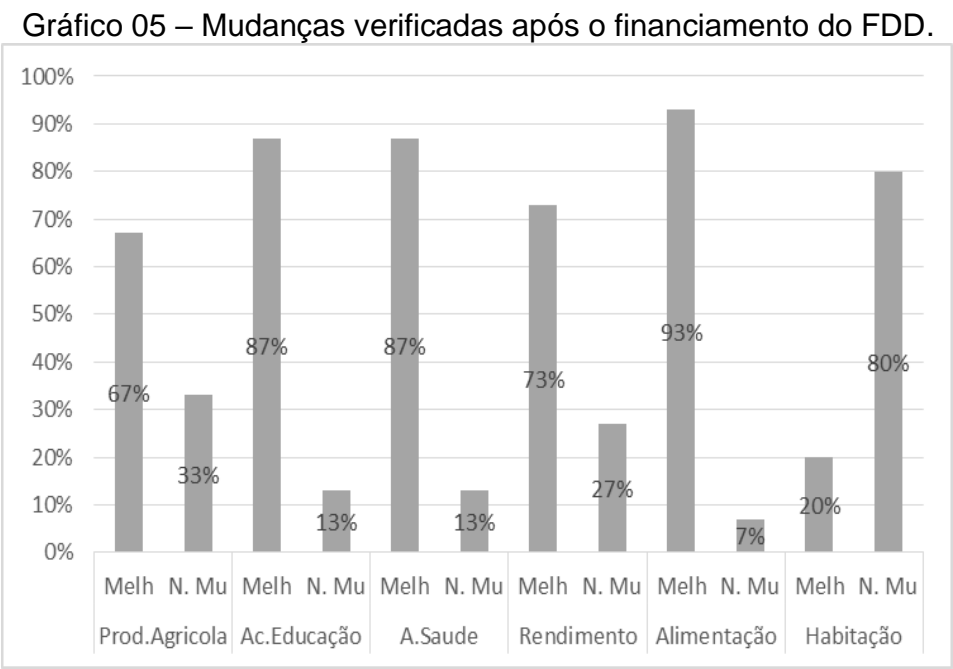

Fonte: Trabalho de campo, 2017. Elaborado pelos autores

Dentre inúmeras necessidades básicas, pode-se notar que com os resultados do gráfico 05 , cerca de $87 \%$ dos mutuários daquele posto administrativo, afirmaram que, com o rendimento proveniente da comercialização dos seus produtos, conseguiram melhorar o acesso a educação dos seus parentes e garantir medicamentos para a família. Dos que afirmaram não verificar mudanças na educação através dos seus rendimentos provenientes da produção agrícola, muitos indicaram como razão o fato de não estarem mais residindo com parentes que necessitem de escola, isto é, seus filhos hoje conseguem pagar seus estudos e residem em outros cantos do país.

Todos mutuários têm acesso à telefonia móvel (o que antes não acontecia), 93\% dos mutuários afirmaram ter acesso a alimentação melhorada e $80 \%$ dos mesmos, não conseguiram melhorar sua condição de acesso a água e podem ainda continuar consumindo água imprópria, muitas das vezes retiradas dos poços e furos contaminados. Alguns ainda continuam obtendo água em rios.

No concernente à habitação, somente $20 \%$ dos mutuários constataram mudanças nas suas habitações (que antes eram precárias), depois da obtenção do financiamento para desenvolverem a atividade agrícola. Sobre algumas das mudanças ocorridas após o desenvolvimento da agricultura, com ajuda do financiamento do fundo de desenvolvimento do distrito, transcreve-se, em seguida, o relato feito pela única mulher que foi financiada no posto administrativo sede durante o período em análise:

"Eu sou chefe de família constituída por seis pessoas, sou viúva mas consigo dar de comer ao netos que residem comigo, tudo isso graças ao dinheiro dos sete milhões que pedi emprestado por duas vezes tendo amortizado a primeira dívida em 2013 e contraído outra ano passado (...), quando doente pelo menos paracetamol e outros comprimidos consigo comprar sem depender muito dos meus filhos, tenho minha conta bancária e faço poupança sempre que 
possível (...) estou terminando minha obra que estava paralisada há anos e até assisto DSTV ${ }^{8}$ em casa" (Agricultora financiada pelo FDD, 08.06.2017).

No que concerne a mudança verificada no bem-estar dos mutuários e as suas respectivas famílias, tendo como base os resultados verificado no gráfico 05 concluise que houve uma melhoria no bem-estar. Os resultados mostram a melhora de alguns indicadores, como são os casos de educação, saúde, telefonia móvel e alimentação. Porém, os mesmos resultados mostram que apesar da melhora verificada, os agricultores (mutuários) e as suas respectivas famílias debatem-se ainda com o problema da falta de água potável e habitações precárias, o que as tornam ainda desprovidas de algumas condições básicas de sobrevivência.

Sen (2000, p.78) identifica várias liberdades instrumentais que contribuem direta ou indiretamente para a liberdade global que as pessoas têm para viver como desejariam. O autor aponta "as liberdades políticas; facilidades econômicas; oportunidades sociais; garantia de transparência e segurança protetora". Sendo assim, os resultados desse estudo mostram que algumas liberdades instrumentais estão presentes no posto administrativo Sede, o que mostra que as pessoas já têm alguma capacidade de viver mais livremente. Liberdade para Sen é o fim primordial e o principal meio de desenvolvimento (SEN, 2000).

É nesse sentido, que consideradas as liberdades instrumentais propostas por Sen e conjugados com as informações da pesquisa, os resultados mostram que algumas liberdades instrumentais estão presentes, nomeadamente, as oportunidades sociais (saúde e educação foram dimensões em que $87 \%$ da famílias identificaram melhorias nos acessos) e segurança protetora (alimentação, com melhoria percebida por $97 \%$ das famílias que acessaram aos recursos). No caso da educação, essa percentagem mostra que os filhos, netos, primos dos mutuários passaram a ter acesso a educação, isso pode significar que, a médio prazo, uma das dificuldades relatadas pelos mutuários e população em geral seja minimizada, uma vez que haverá mais gente com capacidade de elaborar um projeto e remeter ao conselho consultivo distrital, do posto administrativo ou mesmo da localidade, para posterior aprovação e acesso ao financiamento.

\section{PRINCIPAIS PROBLEMAS ENFRENTADOS PELOS MUTUÁRIOS DO FDD}

Todos mutuários do FDD que financiaram projetos com o objetivo de produzir comida, apontaram as calamidades naturais como sendo o maior constrangimento que os preocupa. Dentre várias calamidades, todos mutuários apontaram as cheias como a principal causa do fraco aceleramento das suas atividades (agricultura).

Quando há cheias aqui fica tudo parado, não faço mais nada até isto secar. Por exemplo em 2014, eu praticamente não produzi nada, só para fazer lavoura era problema, os bois não aguentavam porque a machamba estava muito cheia de água principalmente eu que minha machamba está no machongo ${ }^{9}$. Pelo menos eu que cultivo lá na zona baixa prefiro que não caia chuva porque água sempre tenho para regar (Mutuário do FDD, Localidade de Maniquinique em 18/05/2017).

\footnotetext{
${ }^{8}$ A Digital Satellite Television (DSTV) é um serviço de televisão digital da MultiChoice que opera na África subsariana. O serviço foi instituído em 1995. Informação disponível através de https://www.dstv.com/pt$\mathrm{mz} /$ news/a-dstv-em-moambique-20160729. Acesso em 14/outubro/2018.

${ }^{9}$ São solos hidromórficos orgânicos, conhecido localmente por Machongos. São solos cinzentos muito escuros a negros, muito rico em matéria orgânica, de textura variando entre arenoso a argiloso e com abundância de água, o que impede a rápida decomposição da matéria orgânica.
} 
Apesar de ter sido concedido o crédito pelo Governo, a maioria dos beneficiários ficou insatisfeito com o valor que lhe foi concedido, visto que, os valores que lhes foram financiados não corresponderam com o proposto no orçamento do projeto. Dos agricultores do Posto Administrativo Sede, que se beneficiaram do fundo, apenas de $27 \%$ deles disseram sentir-se satisfeitos com o valor financiado. Os insatisfeitos reclamaram por motivos similares, vejamos a seguir o relato de um dos mutuários insatisfeito com a situação acima relatada:

[...] Eu pedi 150,000,00 meticais mas só me deram a metade e esse valor não correspondeu ao plano de atividades que eu tinha programado, assim sendo, me senti obrigado a descartar algumas atividades e isso comprometeu minha produção [...] dinheiro não chegou para cobrir todas as despesas, só chegou para comprar motobomba, custear despesas de transporte, mas acabei por não comprar tubos para transportar água do rio para meu campo de produção, o resto acabei deixando para fazer lavoura, gradagem e comprar alguns insumos, tubos só ano passado é que comprei com dinheiro que consegui obter com a produção [...] esse dinheiro que me deram eu só aceitei porque não é mesma coisa com não ter, mas para falar verdade esse dinheiro não chegou para o que eu queria fazer " (Agricultor da Localidade de Maniquinique em 08.06.2017).

Outro constrangimento enfrentado pelos mutuários está ligado as infraestruturas. Os mutuários têm problemas em escoar e armazenar seus produtos até ao mercado, pois, as vias de acesso partindo do local de produção à estrada pavimentada encontra-se em condições desfavoráveis. Dessa forma, chegada a safra, preferem entregar seus excedentes aos intermediários (retalhistas) que operam no mercado central do distrito de Chibuto que muitas vezes aparecem com seus meios de transporte. Sendo assim, acabam por praticar a preços baixos, ou seja, acabam tendo menor poder de barganha.

Outro problema evidenciado na pesquisa têm relação com a atualização da divida contraída a partir da aprovação e concessão do recurso ao projeto. Existem mutuários que não sabem em que situação financeira se encontram. Portanto, pedem que o governo, os atualize periodicamente sobre as amortizações do crédito, visto que, só depositam sem saber em que estágios se encontram do pagamento do financiamento, o que inviabiliza um controle econômico e financeiro adequado para o reembolso dos recursos disponibilizados e, consequentemente, a manutenção do fundo.

\subsection{CONSTRANGIMENTOS GERAIS LIGADAS AO FDD}

Essa aparente falta de critérios claros para o uso dos fundos deu origem a diversas interpretações sobre o mesmo e, em muitos casos, deu margens a irregularidades. Nesse sentido são reportados alguns casos. Percebe-se a ocorrência de discriminação no acesso aos fundos dos "7 Milhões", baseada no pertencimento ao partido no poder, que é fomentada tanto pelos administradores dos distritos como pelos membros dos Conselhos Consultivos dos Distritos (CCD). Essa prática é, constantemente, denunciada pela população durante as visitas presidenciais aos distritos. Ainda mais, o fraco reembolso dos "7 Milhões" em todos os distritos, aliado à ausência de mecanismos eficazes de cobrança dos mutuários, sugere que a não cobrança seja uma atitude deliberada e intencional do partido no poder. Em relação a 
isso, alguns políticos da oposição "dizem não ter dúvidas que a atribuição do valor foi concebida única e exclusivamente para cimentar a hegemonia do partido no poder, a FRELIMO ${ }^{10}$, ao longo do país, principalmente ao nível das comunidades rurais" (MEDIAFAX, 2010).

A par destas irregularidades, pode-se enumerar também a situação dos mutuários (beneficiários) que desaparecem com o dinheiro do Estado ${ }^{11}$, uma vez que o regulamento do fundo advoga que o dinheiro deve ser devolvido para que possa beneficiar a outras pessoas que apresentem novos projetos. Aliado a isso, há existência de beneficiários fantasmas, visto que na tomada de decisão e na gestão do fundo de desenvolvimento do distrito não são inclusos a comunidade local e, consequentemente há falta de transparência e prestação de contas no processo de seleção dos beneficiários do fundo.

A questão dos financiamentos não correspondentes ao orçamento proposto nos projetos é outro dilema enfrentado pelos mutuários. Ou seja, este problema origina a descapitalização. Alocar dinheiro insuficiente em qualquer projeto de investimento é arriscado, principalmente aos do setor agrícola. Torna-se mais arriscado ainda quando o mesmo dinheiro é gerenciado por agricultores com baixa capacidade de gestão.

No entanto, para que essas irregularidades mencionadas não ocorram, seria necessária uma reestruturação do fundo, acompanhada de medidas socioeducativas em que o sujeito proponente fosse visto como protagonista do processo social e em que se buscasse ampliar sua autonomia.

\section{CONSIDERAÇÕES FINAIS}

Após a realização de pesquisa, foram tiradas as seguintes conclusões: o desenvolvimento tem que ser visto como um processo multidimensional, envolvendo mudanças nas estruturas, nos comportamentos e nas instituições. Também deve acelerar o crescimento econômico, tendo como objetivos promover a redução das desigualdades e a erradicação da miséria.

Também ficou patente que algumas liberdades instrumentais que Sen classifica como fim primordial e o principal meio de desenvolvimento, foram atendidas no posto administrativo Sede com o acesso aos recursos do Fundo, são os casos de oportunidades sociais (que foram aumentadas com a melhoria do acesso à saúde e educação quando os beneficiários tiveram acesso ao fundo) e segurança protetora (considerando o caso de percepção da melhoria no acesso à alimentação).

O Orçamento de Investimento de Iniciativa Local (OIIL) ou simplesmente Fundo de Desenvolvimento do Distrito (FDD) foi criado com o intuito de contribuir para a redução da pobreza através do financiamento de projetos individuais de produção de comida e de geração de emprego e renda. Portanto, os resultados deixaram bem claro que, apesar da melhoria a alguns acessos, há muito a se fazer para que o FDD exerça na verdade a função que motivou a sua criação, promover a autonomia e a melhoria na qualidade de vida das pessoas

No distrito de Chibuto, de 2010 a 2016, foram financiados 777 projetos (destes 191 projetos foram financiados no posto administrativo Sede), dos quais 165 destinou-se a agricultura e o remanescente aos outros setores privilegiados pelo FDD.

\footnotetext{
10 A Frente de Libertação de Moçambique, também conhecida por seu acrónimo FRELIMO, é um partido político oficialmente fundado em 25 de Junho de 1962 (como movimento nacionalista), com o objetivo de lutar pela independência de Moçambique do domínio colonial português.

11 Não está ainda claro ou regulamentado o procedimento a ser tomado nos casos em que os beneficiários dos fundos (mutuários) não realizem o reembolso dos valores alocados a eles pelo fundo, isso faz com que muito dos mutuários não se preocupem em reembolsar os valores recebidos.
} 
Dos projetos destinados a produção agrícola (165), somente 25 projetos foram financiados a nível do Posto Administrativo Sede.

Com o financiamento obtido pelos mutuários (agricultores), houve uma melhoria considerável nos índices de produção e produtividade (rendimento), assistiuse a uma significativa melhora nas condições básicas, como são os casos de acesso a educação, saúde, alimentação e telefonia móvel, no entanto, apesar dessa melhora, os dados mostraram que, os mutuários continuam enfrentando vários problemas como são os casos do acesso de água potável e condições precárias das suas habitações.

Outro especto que chama atenção na atribuição do financiamento aos mutuários é a questão do gênero. Os resultados mostram que são os homens os que se beneficiam mais dos fundos. Face a essa particularidade são levantadas as seguintes questões: Será que as mulheres não têm conhecimento da existência do fundo? Será que os projetos propostos pelos homens têm mais peso em relação ao das mulheres? Ou por causa do alto índice de analfabetismo feminino, o acesso ao financiamento pelo FDD torna-se mais restrito? Essas e mais questões, podem ser respondidas em pesquisas posteriores, que são de fundamental importância para o aperfeiçoamento deste importante instrumento de política pública para o desenvolvimento de Moçambique.

\section{REFERÊNCIAS}

CONSELHOS DE MINISTROS. O fundo distrital de Desenvolvimento. Disponível em: www.portaldogoverno.gov.mz. Acesso em: 21 nov. 2018.

FRANCO, A. Por que precisamos de desenvolvimento local, integrado e sustentável. Brasília: Editora Millennium, 2000.

INÁCIO, N. Como tornar o distrito um verdadeiro polo de Desenvolvimento. Disponível em: http://noainacio.blogspot.com/2007/07/como-tornar--distrito-umverdadeiro.html. Acesso em: 13 dez. 2016.

MEDIAFAX. É preciso ver o impacto dos sete milhões e não os níveis de devolução. Disponível em: https://noticias.sapo.mz/jornais/nacional/4881/2010. Acesso em: 17 de ago. 2017.

INE. Estatísticas do distrito de Chibuto. Disponível em: http://www.ine.gov.mz/estatisticas/estatisticas-territorias-distritais/gaza/novembro-de2013/distrito-de-chibuto.pdf/view. Acesso em: 23 de jul. 2017.

MUTEIA, H. A importância do microcrédito para o desenvolvimento agrícola. Disponível em: http://opais.sapo.mz/index.php/opiniao/158-helder-muteia/32814-aimportancia-do-microcredito-para-odesenvolvimentoagri.html?tcomponentprint.

Acesso em: 20 de Jun. 2017.

OLIVEIRA, S. V.; VIEIRA, C. A.; PAULI, R. I.P. Desenvolvimento rural no Rio Grande do Sul (2010/2013): uma análise multidimensional. Extensão Rural, Santa Maria, v.25, n.3, p.28-45, jul./set. $2018 . \quad$ Disponível em: https://periodicos.ufsm.br/extensaorural/article/view/30838/pdf. Acesso em 20 jun. 2017.

SACHS, I. Desenvolvimento: includente, sustentável, sustentado. Rio de Janeiro: Editora Garamond, 2004. 
SANTOS, E. et al. Desenvolvimento: um conceito multidimensional. Revista Eletrônica do Programa de Mestrado em Desenvolvimento Regional da Universidade de Contestado, Brasil, Ano 2, n.1, p. 44-61, jul. 2012.

SEN, A. O desenvolvimento como expansão das capacitações. Revista de cultura e política. n. 28. CEDEC, São Paulo, p.1-11, 1993.

SEN, A. Desenvolvimento como liberdade. São Paulo: Companhia de Tetras, 2000.

SEN, A. Desigualdade reexaminada. Rio de Janeiro: Editora Record, 2000.

SITOE, T. A. Agricultura familiar em Moçambique estratégias de Desenvolvimento Sustentável. Disponível em: www.mpd.gov.mz. Acesso em: 13 maio. 2017.

VALÁ, S. O orçamento de investimento de iniciativa local e a dinâmica da economia rural em Moçambique: resultados, desafios e perspectivas: economia, política e desenvolvimento. Revista Científica Interuniversitária. Maputo, v.1, n.2, p.17-35, 2010.

VEIGA, J. E. O Brasil rural ainda não encontrou seu eixo de desenvolvimento. Estudos Avançados, v.15, n.43, p. 101-119, 2001. 